\title{
Influence of La-impurities and Plasma Treatment on the Structural and Optical Properties of Some Bismuth Calcium Borate Glasses
}

nasra mohamed ( $\sim$ nasrabinaya@yahoo.com )

Al-Azhar University

Hosam M. Gomaa

Independent research

H. A. Saudi

Al-Azhar University

raed $M$. el shasly

Al-Azhar University

W. M. El-Meligy

Al-Azhar University

F. M. El-Hossary

Sohag University

\section{Research Article}

Keywords: Lanthanum, Glass, RF Plasma, Hardness, Elastic deformation, Optical measurements

Posted Date: June 17th, 2021

DOl: https://doi.org/10.21203/rs.3.rs-574905/v1

License: (c) (i) This work is licensed under a Creative Commons Attribution 4.0 International License.

Read Full License 


\title{
Influence of La-impurities and plasma treatment on the structural and optical properties of
} some bismuth calcium borate glasses

\author{
N. M. Ebrahema, Hosam M. Gomaa ${ }^{\text {b }}$, H. A. Saudi ${ }^{a}$, R. M. El Shazlyc, W. M. El-Meligy ${ }^{\text {a }}$, and F. M. El-
} Hossary ${ }^{\mathrm{d}}$.

${ }^{a}$ Physics Department, Faculty of Science (Girls Branch), Al-Azhar University, Cairo, Egypt.

${ }^{\mathrm{b}}$ Independent Researcher, Sakkara. Giza, Egypt.

${ }^{c}$ Physics Department, Faculty of Science (Boys Branch), Al-Azhar University, Cairo, Egypt.

${ }^{\mathrm{d}}$ Physics Department, Faculty of Science, Sohag University, Sohag, Egypt.

\section{Abstract}

This research work aims to the estimation of the effect of the addition of $\mathrm{La}_{2} \mathrm{O}_{3}$, by different amounts in wt. \%, to the matrix of the bismuth calcium borate glass. The fast cooling procedure was used to prepare the suggested compositions. XRD was used to inspecting the internal structural phases of the prepared samples, where XRD patterns confirmed the amorphous natures of all samples. It was found that the La-additives act to increase the glass density, micro hardness, and optical absorption. While the plasma treatment using $\mathrm{N}_{2}$ acted to reduce both the relative intensity of XRD and the optical absorption.

Keywords: Lanthanum, Glass, RF Plasma, Hardness, Elastic deformation, Optical measurements.

\section{Corresponding Author: Nasra M. Ebrahem}

(Email: nasrabinaya@yahoo.com)

\section{Introduction}

Though the last few decades, different glass systems doped with rare earth elements has great importance because of their special properties and potential applications in solid-state lasers, optical amplifiers and three-dimensional displays, planar waveguide, optoelectronic devices such as short wavelength lasers, sensors and, high-density frequency domain optical data storage[1-2]. By a short survey on the applications of lanthanum-based materials, it can be concluded that such materials have a widespread in optical devices. For example, Lanthanum is used in equipment such as color televisions, fluorescent lamps, energy-saving lamps, and glasses. $\mathrm{La}_{2} \mathrm{O}_{3}$ is used in the glasses fabrication to improve their optical properties for infrared adsorbingglasses that used to fabrication the lenses of the camera and telescopes. Also, Lanthanum is used in large quantities in nickel-metal hydride rechargeable batteries. By the way, in 1974 the French researchers at the University of Rennes had discovered types of lanthanum-based fluoride glasses called ZBLAN, which is composed of zirconium, barium, lanthanum, aluminum, and sodium. 
This glass showed potential applications as an optical fiber material that can be used in fabrication-processes in communications tools and medical devices [3]. Bismuth oxide based glasses have much interest because of their premium optical properties which make them a good applicant in the range of glass ceramics, reflecting windows, layers for optical and electronic devices, third order optical nonlinear materials and other photonic devices[4]. $\mathrm{Bi}_{2} \mathrm{O}_{3}$ is known as a heavy metal oxide and the glass containing $\mathrm{Bi}_{2} \mathrm{O}_{3}$ have minimum rates of crystallization, higher density, great optical basicity, high optical susceptibility, high refractive index, high polarizability and nontoxicity [5-6]. Boric acid $\left(\mathrm{B}_{2} \mathrm{O}_{3}\right)$ is one of the common and fine glass formers that form glass at lower melting point solely by itself, good rare-earth ions solubility, good transparency and lower price [7-8-9].Also the boron-oxygen groups frequently participate to nonlinear optical effects along with alkaline earth cations, the thing that makes them good candidates for nonlinear and optoelectronic applications [10]. Glasses doped with rare earth ions can be used as luminescence materials due to high emission efficiencies alike $4 \mathrm{f}-4 \mathrm{f}$ and $4 \mathrm{f}-5 \mathrm{~d}$ electronic transitions in the $\mathrm{RE}^{\mathrm{n}+}$. Because of shielding imparts of the outward 5S and 5P orbitals on the $4 \mathrm{f}$ electrons, the $4 \mathrm{f}-4 \mathrm{f}$ transition gives a particularly sharp fluorescence patterns from the ultra violet to the infra-red region [11-12]. Also, material surface modification is a very important issue in industrial applications, which always adjust the output quality with processing costs. For example, various surface plasma treatment techniques are applied to restore mechanical performance and to increase the life of materials for use in different applications [13]. Radio frequency (rf) plasma with nitrogen gaseous used for surface modification alter the surface characteristics of materials while maintaining the bulk properties. (rf) plasma nitriding is superior and most developed method having a lot of advantages over the other methods. In an (rf) plasma process, nitrogen is one of the active elements which improve the corrosion resistance and wear of alloys [14]. Plasma treatment modifies the surface properties of materials resulting in changes extending from a few nanometers to $\sim 10$ micro meters without affecting the bulk property of the material, a diversity of chemical structures can be generated also surface chemistry can be controlled. Plasma treatment affords control over hardness, chemical inertness and wettability. Plasma modified materials exhibit amended response characteristics when in connect with biological environment [15]. A. M. Shams. et al. studied the enhancement mechanical properties of YBIBO3 glasses using $\mathrm{La}_{2} \mathrm{O}_{3}$. This study found that the increment of $\mathrm{La}_{2} \mathrm{O}_{3}$ increased the bridging oxygen atoms, the cross-link density and the number of 
coordination [16]. F. EL-Hossary et al. investigated the effect of (rf) plasma time on the carbonitriding treatment of titanium. They examined the effects of different plasma-processing times on mechanical Properties and the microstructure of plasma-carbonitrided Ti. The surface micro hardness and the thickness of the compound layer of carbonitrided Ti increment with the plasma processing time [17]. Studying the optical properties of oxide glasses gives us a good sight about their internal electronic environments. For profitable comparison between different optical parameters of the studied glass samples, the transmittance $T$ and the absorption $A$ were measured and plotted. One of the most important optical parameters is the optical absorption coefficient which gives useful information about the electronic state in depressed wavelength and high energy region. It also helps in determining the type of absorption process identified and other obtained linear optical parameters as well [18-19]. The aim of the present work is to prepare and characterize a new class of superior vitreous materials based on bismuth borate glasses co-doped with lanthanum oxide, to study optical properties and to investigate mechanical hardness of the glass system before and after plasma treatment.

\section{Experimental details.}

Glass samples were prepared by melt quenching technique with chemical compositions, $\mathrm{xLa}_{2} \mathrm{O}_{3}-0.4 \mathrm{Bi}_{2} \mathrm{O}_{3}-0.4 \mathrm{~B}_{2} \mathrm{O}_{3}-0.2 \mathrm{CaO}$ where $\mathrm{x}=0,0.02,0.04,0.06$, and 0.08 , After mixed all different chemicals manually in a porcelain crucible in batches of $30 \mathrm{~g}$, resulting homogenous mixture was heated at $1100^{\circ} \mathrm{C}$ for 2 hours. Then quickly poured, annealed and then cooling down to room temperature to remove any internal stress and excessive $\mathrm{OH}^{-}$in the mixture. Circular samples $($ diameter $=3 \mathrm{~cm}$ ) were polished and cleaned with distilled water and ethanol. Then, these samples were plasma-treated for $20 \mathrm{~min}$ in $100 \% \mathrm{~N}_{2}$ gas at a previously evacuated chamber pressure that was $2 \times 10^{-2}$ mbar. After plasma-treatment, these samples were stored under vacuum $\left(8.5 \times 10^{-2}\right.$ mbar). X-ray diffraction (XRD) measurements were carried out using Japan diffractometer employing $\mathrm{Cu}-\mathrm{K} \alpha$ radiation. A Vicker's micro-hardness measurements were made for the surfaces using a standard micro-hardness tester (Shimadzu Corporation HMV ${ }^{\mathbf{2}}$, 50-60 HZ, Japan) for specimen indentation with a contact load of $300 \mathrm{~g}$ for $10 \mathrm{~s}$ before and after

plasma treatment. Finally the optical spectra were recorded using Jasco Spectrometer in the region from $190 \mathrm{~nm}$ to $2500 \mathrm{~nm}$ with a resolution of $4 \mathrm{~nm}$. 


\section{3-Result and discussion:}

\subsection{Structural characterization \& Phase Identification:}

Figure (1) illustrates the normalized $\mathrm{x}$-ray diffraction patterns for $\mathrm{x}=0,0.02,0.04,0.06$, and 0.08 . Those patterns do not show any sharp peak, only a broad hump that characterizes the amorphous solids. It's clear that the relative Intensity of the observable hump increase as the Laimpurities increase. Like this behavior may affect the optical parameters especially the value of the extinction coefficient, also it may indicate somehow conversion from the short-range order phase to the long-range order one, which may mean an increase in the density value as the Laimpurities increase. Figure (2) shows the influence of the Nitrogen plasma, $\left(100 \% \mathrm{~N}_{2}\right)$, treatment on the relative Intensity of $\mathrm{XRD}$, for sample $\mathrm{x}=0.08$ as a representative sample; where the relative intensity decreased after plasma treatment, which may mean relaxation action similar to that of the annealing processes. To clarify the validity of the previous conclusions, the density was measured for each sample, and then plotted in Figure (3) for comparison, where the density is very sensitive to any changes that may occur in the internal structural of a solid material. Figure (3) confirmed the results obtained from XRD-analysis, where the density of the glass increased when La-impurities was increased. Such increase in density values may attributed to the increase of the molecular weight values when adding lanthanum oxide, which is of high density $\left(6.51 \mathrm{~g} / \mathrm{cm}^{3}\right)$.

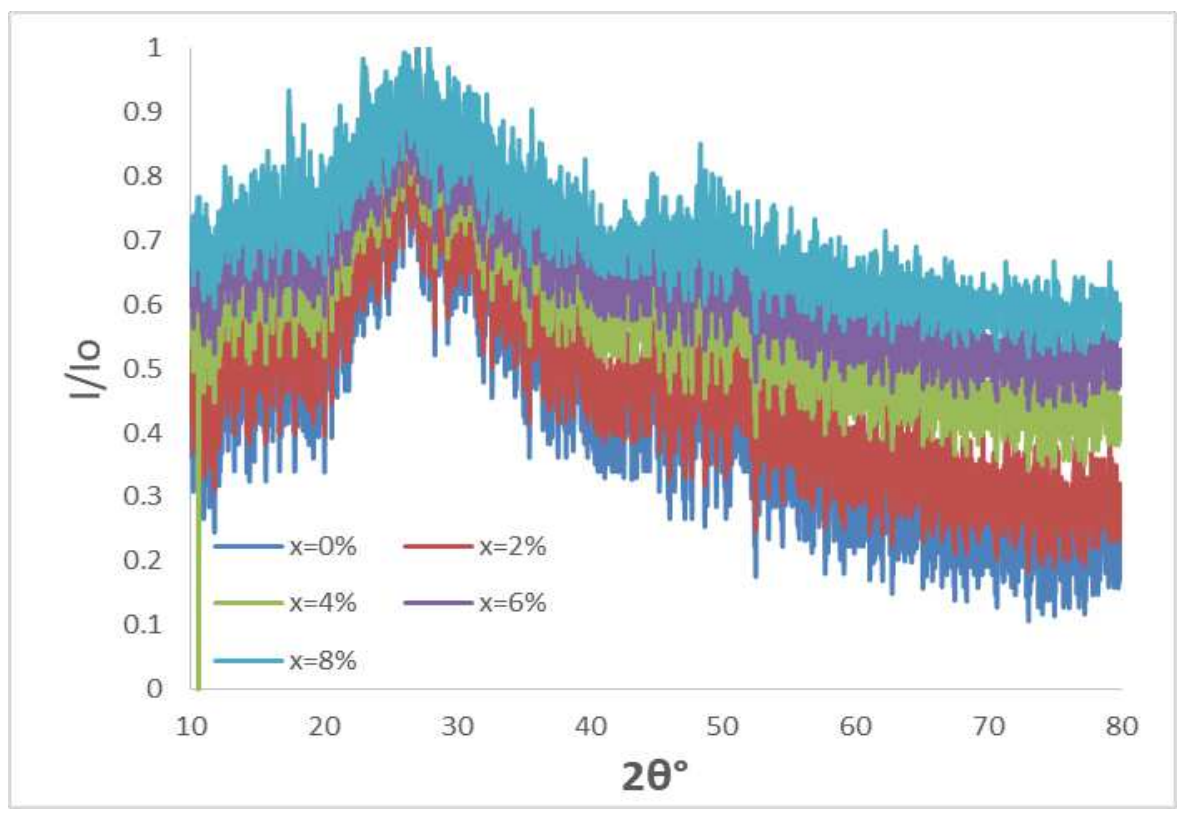


Figure (1): XRD for all sample before plasma treatment

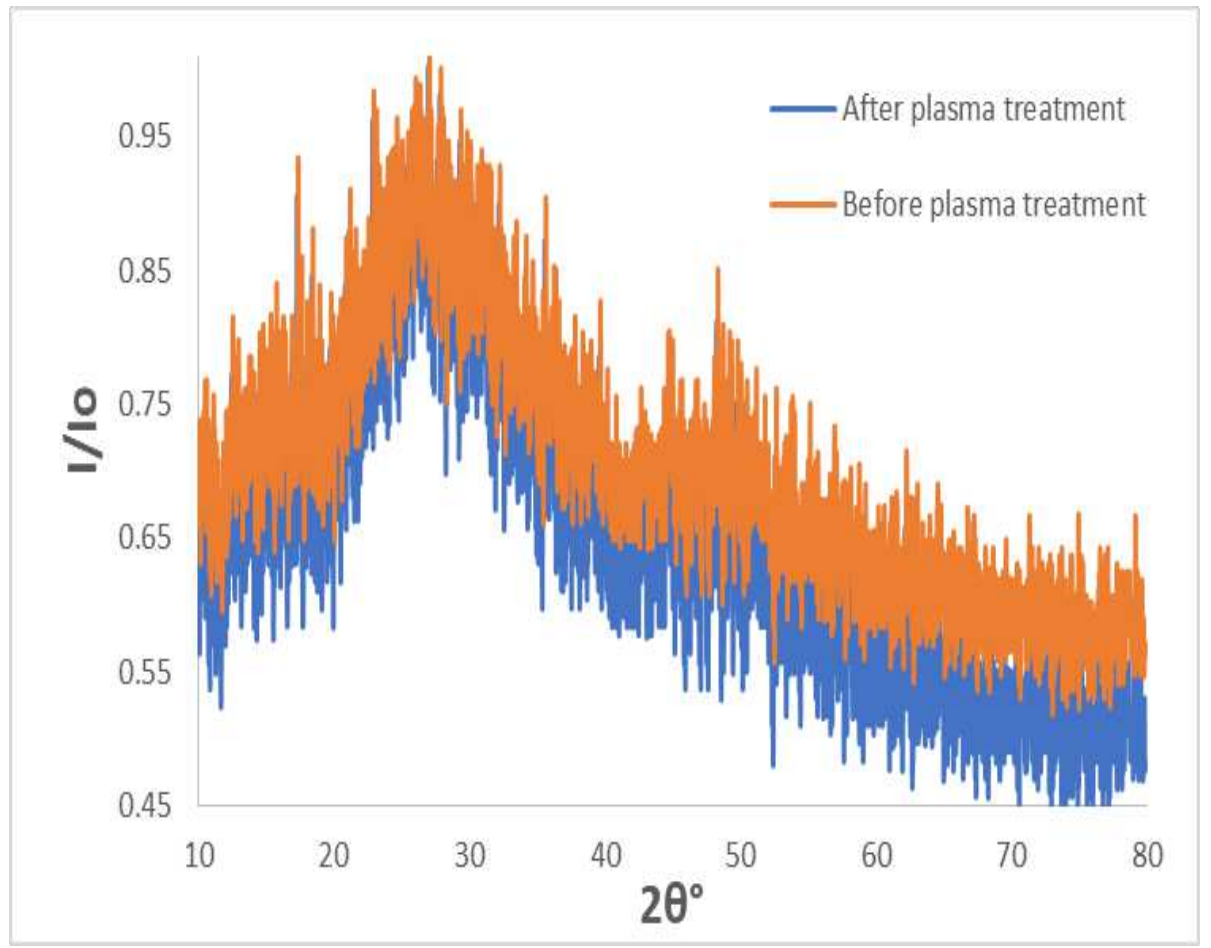

Figure (2): $X R D$ for sample $x=0.08$ before and after plasma treatment.

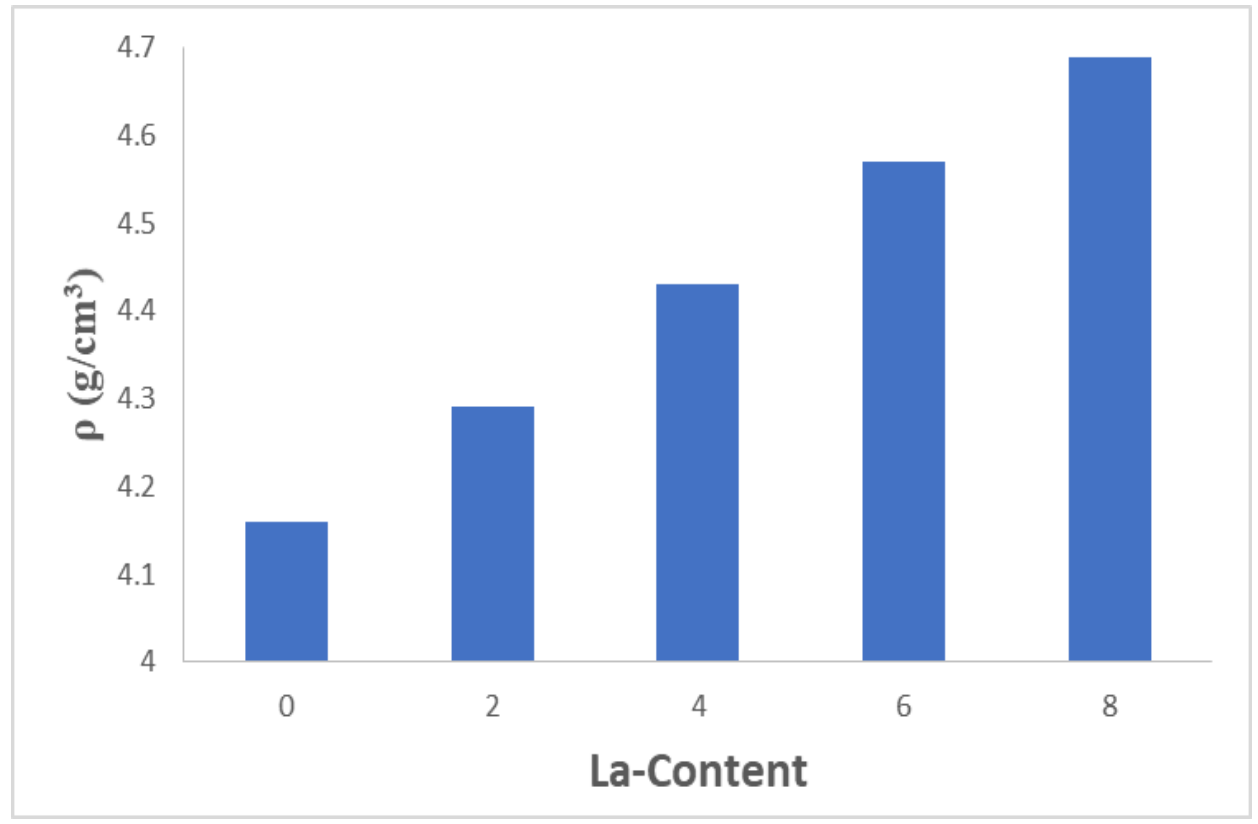

Figure (3): density value La-content 


\subsection{Micro-hardness}

$$
H_{v}=1.854 \frac{F}{d^{2}}
$$

The Vickers micro- hardness values Hv were calculated for all studied samples, before and after the plasma treatment, according to the previous standard formula [22-25]; where $\mathrm{F}$ is the indentation load and $\mathrm{d}$ is the diagonal length impression, as seen in figure (4). It's clear that the incorporation of La-impurities acted to increase the glass hardness (resistance to elastic deformations) as a result to the strength of the atomic bonds in the glass structure induced by dopants [26-29]. On the other side, the plasma treatment causes the hardness of each sample to increase to twice its value before treatment, which may due to a relaxation process as a result of the plasma energies

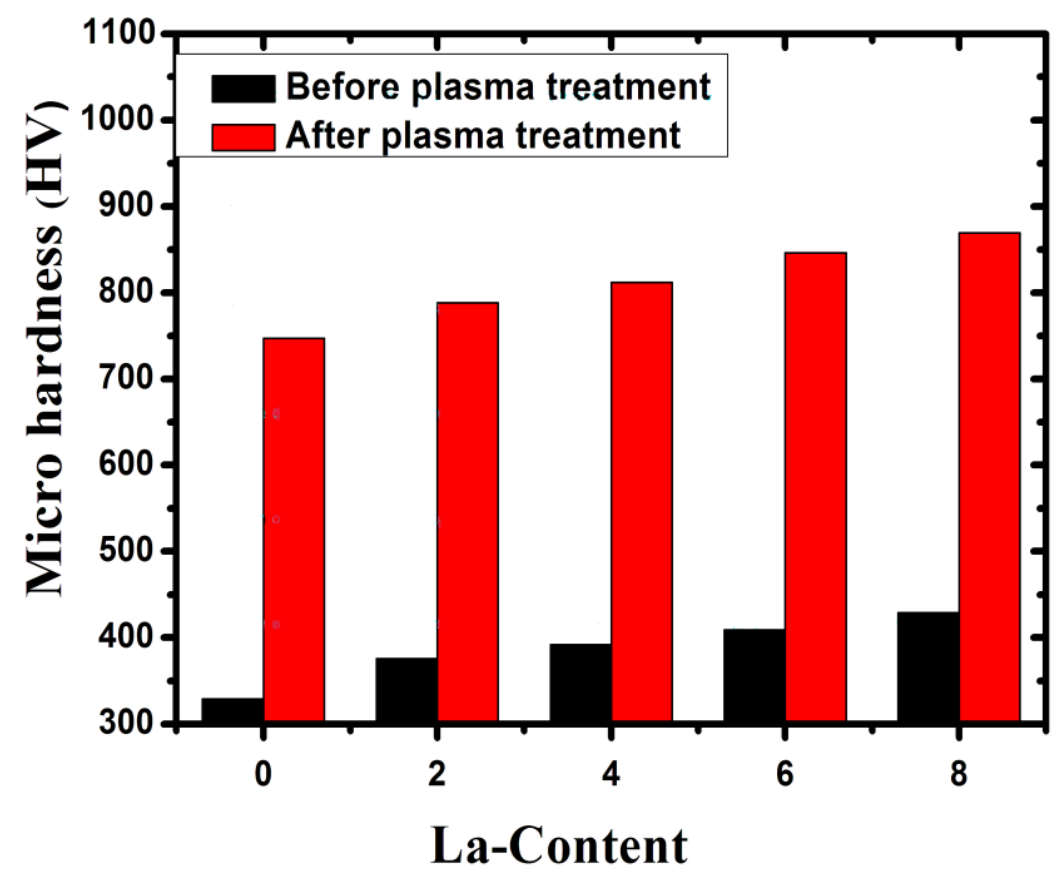

Figure (4): Hardness of $\mathrm{La}_{2} \mathrm{O}_{3}$ content before and after plasma treatment. 


\subsection{Optical Parameters}

Figure (5) depicts both the optical absorbance and the optical transmittance for all studied samples in the range from $400 \mathrm{~nm}$ to $800 \mathrm{~nm}$. Obviously, La-free and La-doped samples have an optical transmission window in the region of visible-near IR, which nominate them from different optoelectronic applications, like the optical switches and or UV-filters. As seen in Figure (5), the increase of La-impurities caused an increase in the optical absorbance because of the relative increase in the value of the bulk density by adding $\mathrm{La}_{2} \mathrm{O}_{3}\left(6.51 \mathrm{~g} / \mathrm{cm}^{3}\right)$ and the increase in the number of oxygen atoms it was found that the plasma treatment causes the optical absorption to decrease to one-half of its value, as seen in Figure (6) for sample $x=0.08$. Such result may suggest the studied glasses as a base of fabrication somehow of optical gas sensors

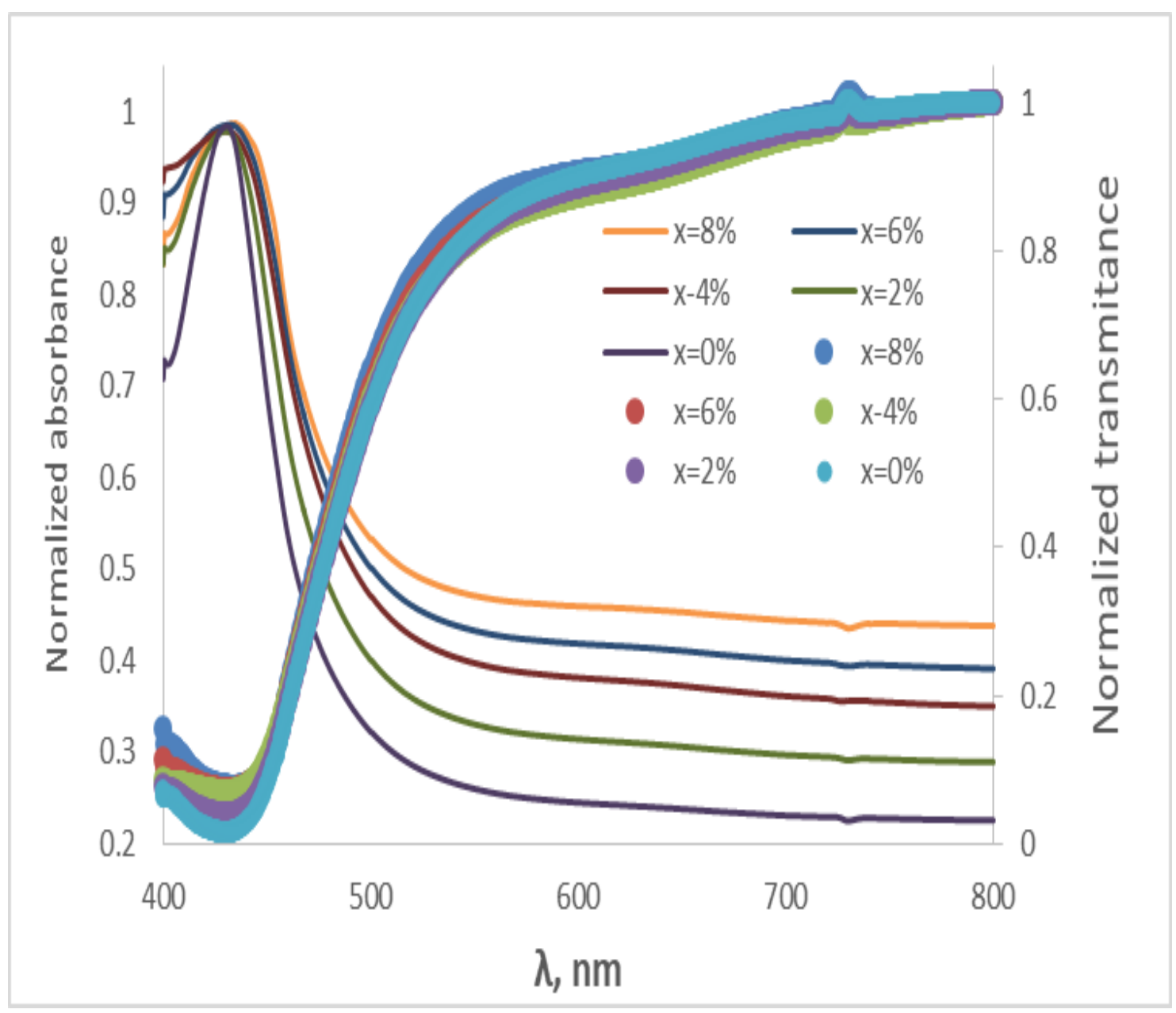

Figure (5): Optical absorbance and transmittance 


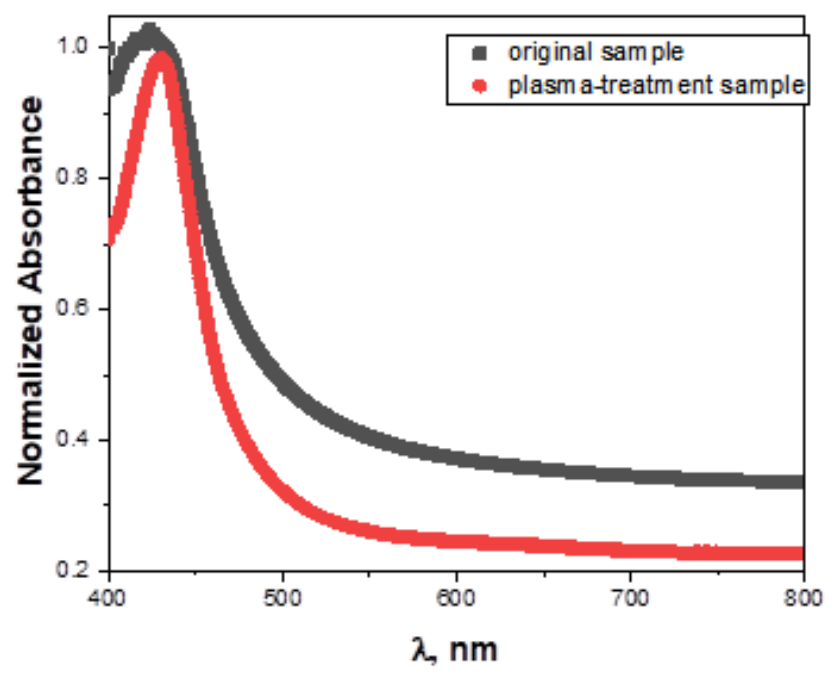

Figure (6): Optical absorbance spectra of $\mathrm{x}=0.08$ before and after Plasma treatment

Based on the Absorbance and transmittance measurements some optical constants and optoelectronic parameters can be calculated, like the optical absorption coefficient $\alpha$, optical band gaps, extinction coefficient $\mathrm{K}$, and the linear refractive index $\mathrm{n}$.

$\alpha=2.303 \frac{A}{t}$

$\alpha(\lambda)=\frac{B}{E}\left(E-E_{\text {direct }}\right)^{\frac{1}{2}}$

$\alpha(\lambda)=\frac{B}{E}\left(E-E_{\text {indirect }}\right)^{2}$

$K=\frac{\alpha \lambda}{4 \pi}$

$n=\frac{1+R}{1-R}+\sqrt{\frac{4 R}{(1-R)^{2}}+K^{2}}$

$R=1-A-T$

Figure (7) exhibits the absorption coefficient as a function of the wavelength, for all samples, it's clear that the absorption coefficient decreases as the wavelength increases in the range 450 to $800 \mathrm{~nm}$. Moreover, $\alpha$ increased when $\mathrm{La}_{2} \mathrm{O}_{3}$ content increased. Since the absorption coefficient $\alpha$ expresses the amount absorbed optical energy per unit volume of a sample for an 
optical process [30,31], it can stated that the light penetration length in the studied glasses decreases with the increasing in $\mathrm{La}_{2} \mathrm{O}_{3}$ content. Using Tuac's relations the optical band gaps for direct and indirect allowed transition were obtained, as seen in figures (8a) and (8b), respectively. It was found that when La-impurities increase both optical band gap decrease from 2.6 to $2.5 \mathrm{eV}$ for direct allowed transition, and from 2.44 to $2.34 \mathrm{eV}$ for indirect allowed transitions, so it can be stated that the incorporation of La cations on the glass composition modify its electronic structure. Figure (9) shows the extinction coefficient $K=(0.08 \alpha \lambda)$, for all samples, versus the energy of the incident light. The extinction coefficient is defined as the parameter which describes the interaction between the electromagnetic radiation and the solid material [32-34], where its value refers to the amplitude of the damping oscillation of the electric field component of the incident light. The K-Value increase as the energy increase from $1.55 \mathrm{eV}$ to $2.47 \mathrm{eV}$, then starts an increase to reaches its maximum of around $2.9 \mathrm{eV}$, this result refers that the studied glasses allow radiation to pass through them high energy loss/max decay in the region of 1.55-2.47 eV. The influence of $\mathrm{La}_{2} \mathrm{O}_{3}$ content on the $\mathrm{K}$-value, where when $\mathrm{La}_{2} \mathrm{O}_{3}$ content increased the $\mathrm{K}$-value increased, in other words the increment of $\mathrm{La}_{2} \mathrm{O}_{3}$ increase the optical energy loss. Figure (10) shows the linear refractive index as a function of the wavelength, for all samples, where the values of the refractive index were obtained from the measured transmission according to relation [35-40].

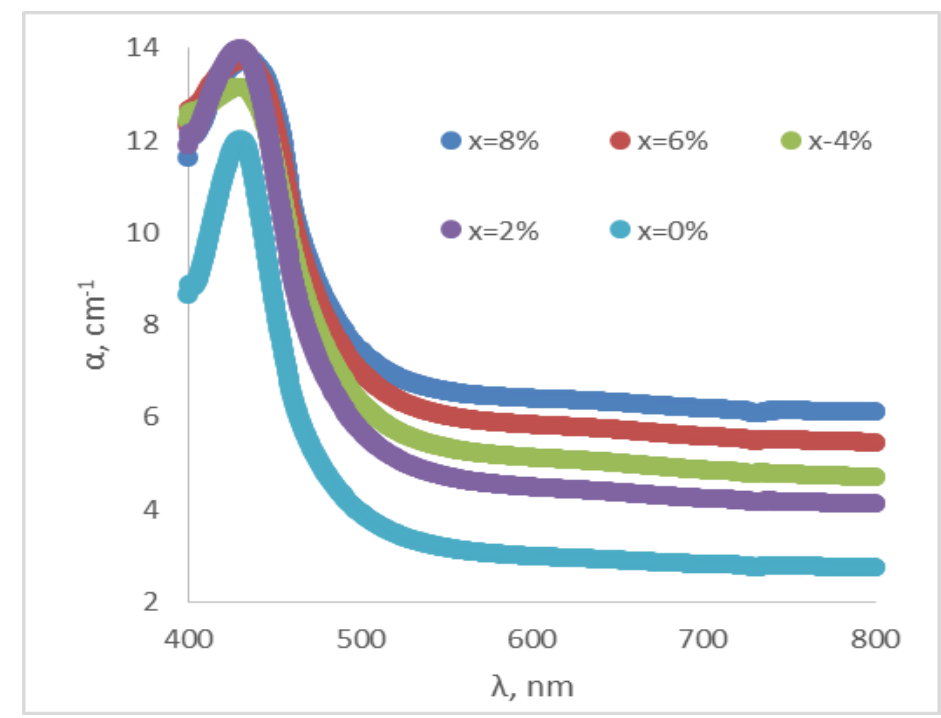

Figure (7): Absorption coefficient ( $\alpha$ ) vs. the wave length $(\lambda \mathrm{nm})$ for different $\mathrm{La}_{2} \mathrm{O}_{3}$ contents. 


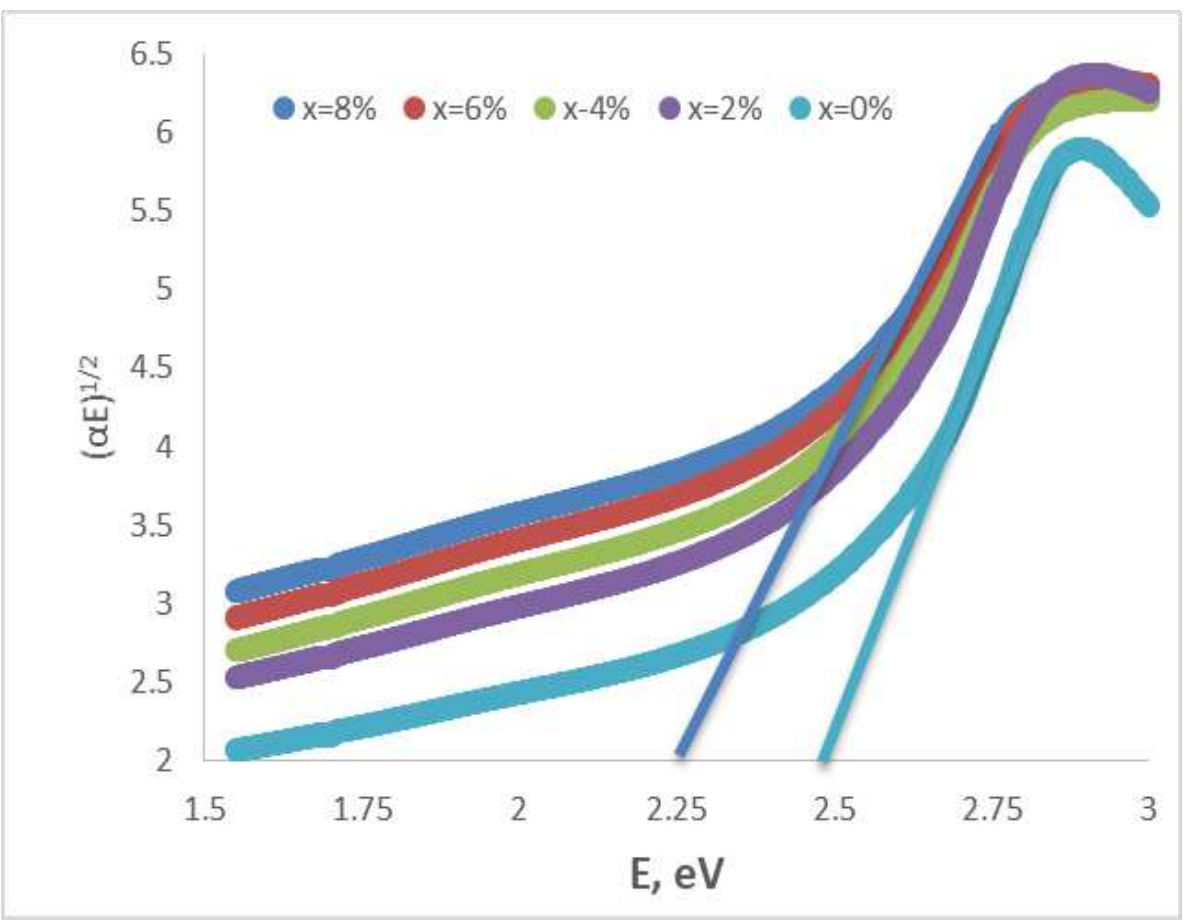

Figure (8a): Plot of $(\alpha E)^{1 / 2}$ versus photon energy $(E=h v)$ of all samples

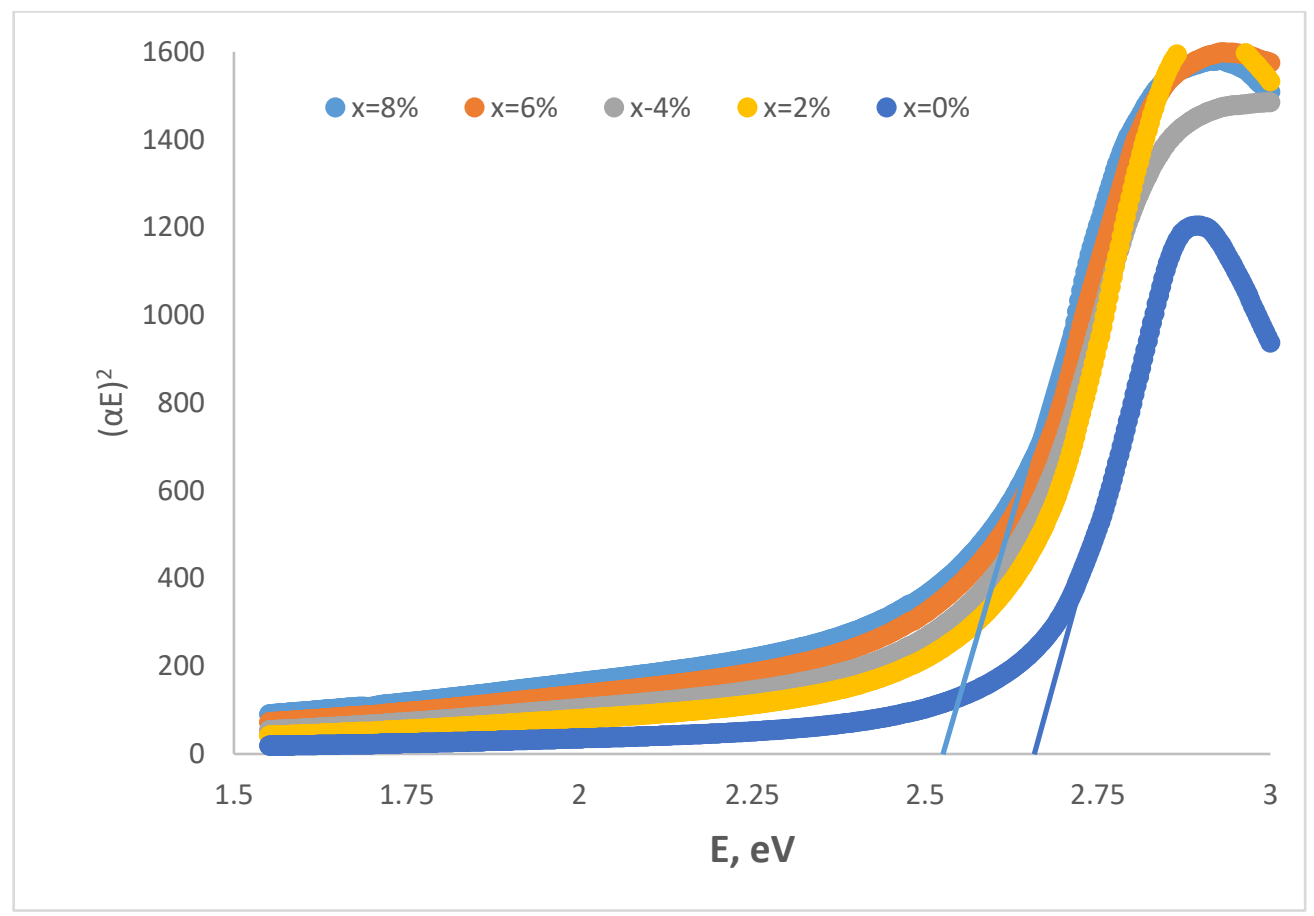

Figure (8b): Plot of $(\alpha E)^{2}$ versus photon energy $(E=h v)$ of all samples 


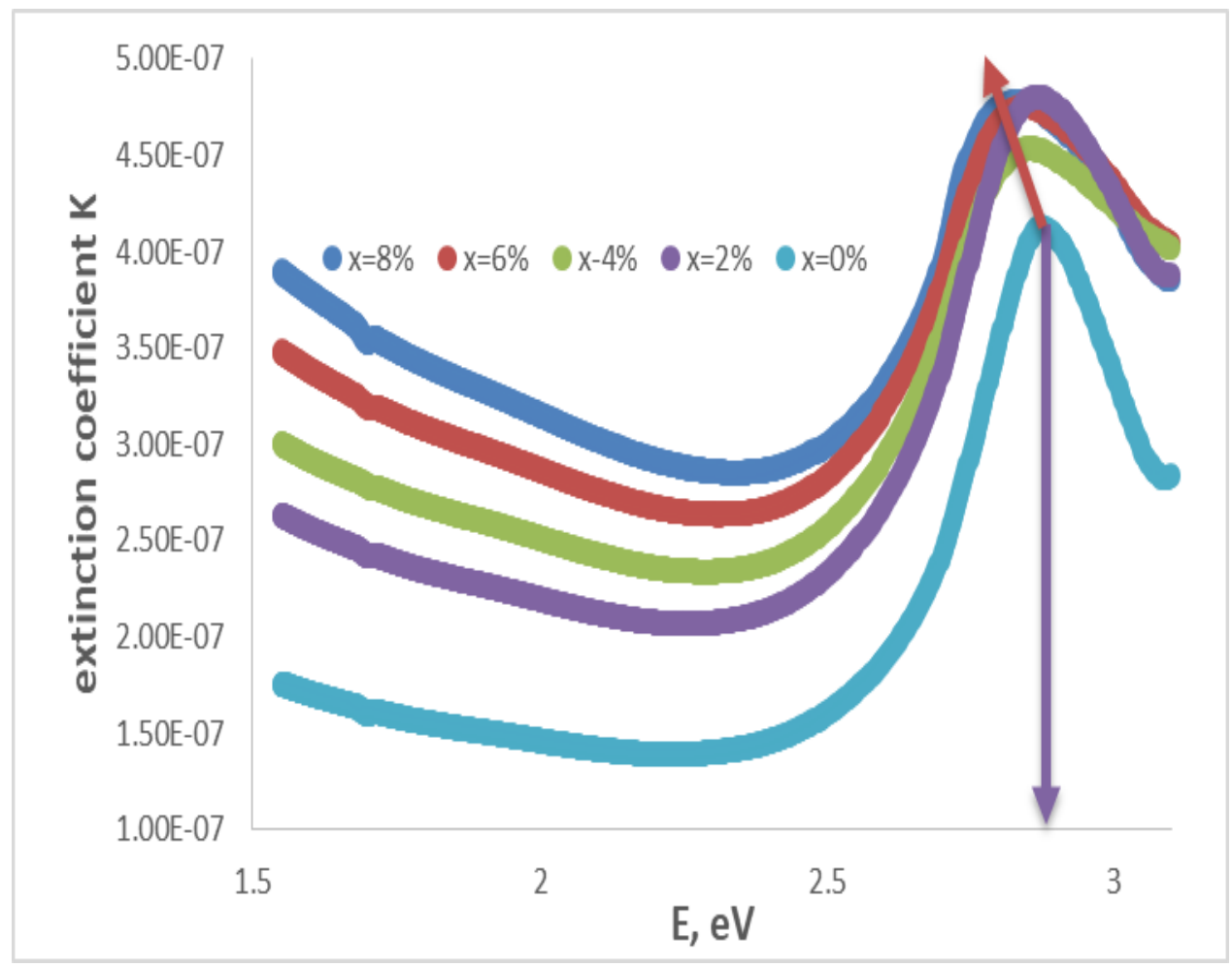

Figure (9): Extinction Coefficient (k) vs. the photon energy, for all samples.

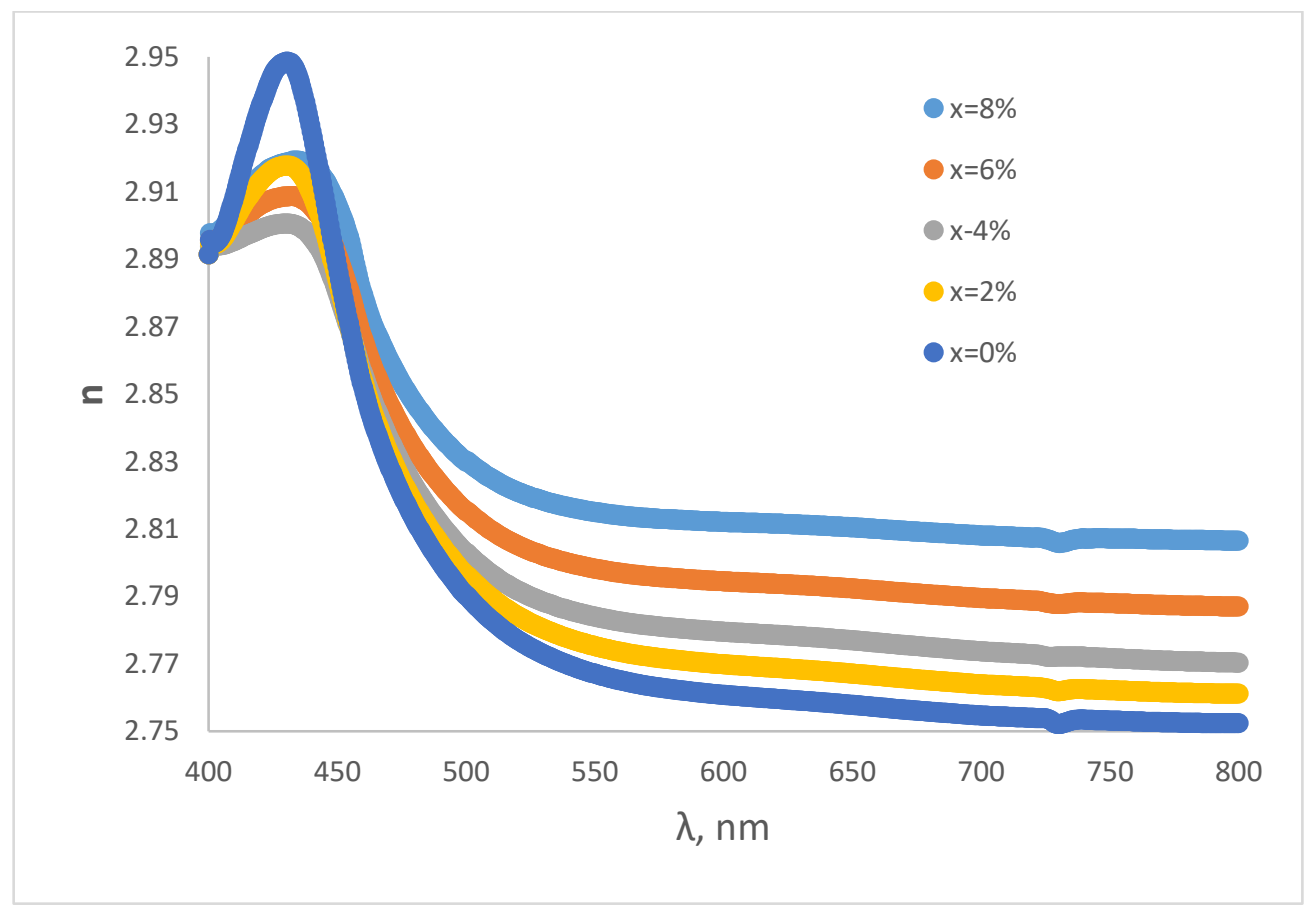

Figure (10): Linear refractive index for all samples $\sim \lambda$ 


\section{Conclusion:}

Some La-free and La-doped bismuth calcium Borate glasses were prepared according to the chemical formula, $\mathrm{x}\left(\mathrm{La}_{2} \mathrm{O}_{3}\right) 0.4\left(\mathrm{Bi}_{2} \mathrm{O}_{3}\right) 0.4\left(\mathrm{~B}_{2} \mathrm{O}_{3}\right) 0.2(\mathrm{CaO})$ where $x=0,0.02,0.04,0.06$, and 0.08, where the fast cooling rate technique was the consider procedure in the preparation process. The results indicated that the mechanical characterization of a bismuth boron matrix mixed with lanthanum and a small amount of calcium oxide strengthens the vitreous structure, resulting in higher values of hardness. A significant increase in the hardness values was observed after plasma treatment of the glass samples due to the formation of a surface layer of nitride on the surface of the glass. Addition of $\mathrm{La}_{2} \mathrm{O}_{3}$ to this studied glass reduced the optical transmittance and increased the absorption coefficient, which means that the length of light penetration decreased with increasing the content of $\mathrm{La}_{2} \mathrm{O}_{3}$. The refractive index was calculated and found to increase with the increase in $\mathrm{La}_{2} \mathrm{O}_{3}$ contents, while the optical transmission decreased. Plasma treatment of $\mathrm{x}=0.08$ showed improvement in the glass transparency but did not change the absorption edge.

\section{Declarations: All the authors declare that there is no conflict of interest.}

\section{References:}

[1]. P. Chimalawong, K. Kirdsiri, et al., 'Investigation on the Physical and Optical Properties of Dy ${ }^{3+}$ Doped Soda-Lime-Silicate Glasses' Procedia Engineering 32 (2012) 690-698. https://doi.org/10.1016/j.proeng.2012.01.1328.

[2]. M. Parandamaiah, K. Naveen Kumar, et al.,' Dy ${ }^{3+}$ doped Lithium Sodium Bismuth Borate Glasses for Yellow Luminescent Photonic Applications' J. Engineering Research And Applications (2015) 126-131.

[3]. Jiawei Gong, Sumathy Krishnan, Chapter 2 - Mathematical Modeling of Dye-Sensitized Solar Cells,

Editor(s): Masoud Soroush, Kenneth K.S. Lau, Dye-Sensitized Solar Cells, Academic Press, 2019, Pages 51-81, ISBN 9780128145418.https://doi.org/10.1016/B978-0-12-814541$\underline{8.00002-1 .}$ 
[4]. Shashidhar Bale and Syed Rahman, ' Electrical conductivity studies of $\mathrm{Bi}_{2} \mathrm{O}_{3}-\mathrm{Li}_{2} \mathrm{O}-\mathrm{ZnO}-$ $\mathrm{B}_{2} \mathrm{O}_{3}$ glasses

'Materials Research Bulletin 47(2012) 1153-1157. doi: 10.1016/j.materresbull.2012.02.007.

[5]. G. Lakshminarayana , S. O. Baki, et al,' Investigation of structural, thermal properties and shielding parameters for multicomponent borate glasses for gamma and neutron radiation shielding applications' J. Non-crystalline solids (2017) 222-137.

https://doi.org/10.1016/j.jnoncrysol.2017.06.001.

[6]. S. Rani, S. Sanghi, et al.,' Influence of $\mathrm{Bi}_{2} \mathrm{O}_{3}$ on physical, electrical and thermal properties of $\mathrm{Li}_{2} \mathrm{O} \cdot \mathrm{ZnO} \cdot \mathrm{Bi}_{2} \mathrm{O}_{3} \cdot \mathrm{SiO}_{2}$ glasses' Journal of Alloys and Compounds 619(2015) 659-666. https://doi.org/10.1016/j.jallcom.2014.09.029.

[7]. P. Yasaka, N. Pattanaboonmee, et al.,' Gamma radiation shielding and optical properties measurements of zinc bismuth borate glasses' Annals of Nuclear Energy 68(2014) 4-9.

[8]. V. Uma, K. Maheshvaran, et al.,' Structural and optical investigations on Dy3+ doped lithium tellurofluoroborate glasses for white light applications'J. Luminescence (2016) 15-24.

[9]. S. Kaewjang, U. Maghanemi, et al., 'New gadolinium based glasses for gamma-rays shielding materials' Nuclear Engineering and Design $280 \quad$ (2014) 21-26. https://doi.org/10.1016/j.nucengdes.2014.08.030.

[10]. R. Chakrabarti, M. Das, et al., 'Emission analysis of $\mathrm{Eu}^{3+}: \mathrm{CaO}-\mathrm{La}_{2} \mathrm{O}_{3}-\mathrm{B}_{2} \mathrm{O}_{3}$ glass'

J. Non- crystalline solids (2007) 1422-1426. https://doi.org/10.1016/j.jnoncrysol.2006.10.067.

[11]. J. Kaewkhao, N. Wantana et al., 'Luminescence characteristics of Dy3+ doped Gd2O3$\mathrm{CaO}-\mathrm{SiO} 2-\mathrm{B} 2 \mathrm{O} 3$ Scintillating glasses, J. rare earths (2016) 583-589. https://doi.org/10.1016/S1002-0721(16)60065-0. 
[12]. P. Chimalawong, K. Kirdsiri, et al., 'Investigation on the Physical and Optical Properties of Dy $^{3+}$ Doped Soda-Lime-Silicate Glasses' Procedia Engineering 32 (2012) 690-698. https://doi.org/10.1016/j.proeng.2012.01.1328

[13] M. Raaif, F. M. El- Hossary, et al.,' Influence of rf-power on the plasma carbonitriding of titanium' Materials Science and Engineering A $480 \quad$ (2008) 271-277. doi: 10.1016/j.msea.2007.07.006.

[14] F. M. El- Hossary, A. M. Abd El-Rahman, et al., ' Effect of rf Plasma Carbonitriding on the Biocompatibility and Mechanical Properties of AISI 321 Austenitic Stainless Steel 'Advances in Materials Physics and Chemistry 4 (2014) 33-42.doi: 10.4236/ampc.2014.42006.

[15]. G. Kaklamani, N. Mehrban, et al.,' Nitrogen plasma surface modification enhances cellular compatibility of aluminosilicate glass' Materials Letters111 (2013) 225-229. https://doi.org/10.1016/j.matlet.2013.08.108

[16]. Shams A. M. Issa, Atif Mossad Ali, et al., 'Enhancement of nuclear radiation shielding and mechanical properties of $\mathrm{YBiBO}_{3}$ glasses using $\mathrm{La}_{2} \mathrm{O}_{3}{ }^{\prime} \mathrm{Nuclear}$ Engineering and Technology (2020)1297-1303. https://doi.org/10.1016/j.net.2019.11.017.

[17]. M. Raaif, F. M. El-Hossary, et al., 'The influence of rf plasma time on the carbonitriding treatment of titanium'. Appl. Phys. A 89 (2007) 467-474. doi: 10.1007/s00339-007-4168-5.

[18]. Hossam Mohamed Gomaa, I. S. Ali et al.,' Linear/nonlinear optical parameters of niobiumfree and niobium-doped bismuth borate glass samples 'Applied Physics A (2020) 126:384. https://doi.org/10.1007/s00339-020-03552-Z

[19]. C. Maghanga,' Influence of deposition parameters on optical properties of sputtered tungsten oxide films' J. Thin Films Sci. Technol. (2018) 61-65. https://doi.org/10.18576/ijtfst/070202

[20]. M. K. Halimah, M. F. Faznny et al.,' Optical basicity and electronic polarizability of zinc borotellurite glass doped $\mathrm{La}^{3+}$ ions' Results in Physics 7 (2017) 581589.https://doi.org/10.1016/j.rinp.2017.01.014.

[21]. T. Z. Amer, R.M. El shazly, et al.,' Study of the Physical and nuclear properties of liquid $\mathrm{PbBiCd}$ Alloy Coolant in nuclear fast reactor', Journal of Nuclear Materials 522(2019)226235. https://doi.org/10.1016/j.jnucmat.2019.05.006. 
[22]. H. M. Gomaa, I. Researcher, H.A. Saudi, et al. 'Physical and structural studies of Some Bismuth Borate Glasses doped with $\mathrm{La}^{3}{ }^{+}$ions' American Journal of Engineering Research (2021)16-23.

[23]. A. S. Abouhaswa, H.M.H. Zakaly et al.,' Synthesis, physical, optical, mechanical, and radiation attenuation properties of $\mathrm{TiO} 2-\mathrm{Na} 2 \mathrm{O}-\mathrm{Bi} 2 \mathrm{O} 3-\mathrm{B} 2 \mathrm{O} 3$ glasses', Ceram. Int. 47 (2021) 185-204. https://doi.org/10.1016/j.ceramint.2020.08.122.

[24]. H.A. Saudi and S.U.E. Kameesy 'Effect of barium addition and plasma nitriding treatment on chemical and physical properties of $\mathrm{Al}, \mathrm{Pb}$ borate glass system as a developed radiation shield' J. Phys. Conf. Ser. 1253 (2019). https://doi.org/10.1088/1742-6596/1253/1/012033.

[25]. Chris Jofeh Arup, UK,"Strength and durability of glass",Chapter 69, ICE Manual of Construction Materials Institution of Civil Engineers ( 2009 ) p.807. doi: $\underline{10.1680 / \mathrm{mocm} .35973 .0807}$

[26]. H. A. Saudi," Gamma Ray Irradiation Effects on the Mechanical and Chemical Properties of $\mathrm{CuO}-\mathrm{Bi}_{2} \mathrm{O}_{3}-\mathrm{SiO}_{2}$ Glasses" American Journal of Physics and Applications, 4,(2016)140-44. doi: 10.11648/j.ajpa.20160406.11

[27]. Heba A. Saudy, Sawsan El Mosallamy, et al.," Mechanical, Thermal and Chemical Durability Behaviors of CdO-Bi $\mathrm{O}_{3}$ Boro-Phosphate Glasses Containing $\mathrm{Fe}_{2} \mathrm{O}_{3}$ ". World Journal of Condensed Matter Physics, 3 (2013) 9-13. doi: 10.4236/wjcmp.2013.31002.

[28]. M. Karabulut , B. Yuce," Effect of boron addition on the structure and properties of iron phosphate glasses," Journal of Non-Crystalline Solids 357 (2011) 1455-1462. https://doi.org/10.1016/j.jnoncrysol.2010.11.023.

[29]. H. A. Saudi, A. Abd-Elalim, et al.," Structure and Physical Properties Study of Some Oxide Glasses Used as $\gamma$ - Ray Shielding Material", Nature and Science 13(11) (2015). doi:10.7537/marsnsj131115.19.

[30]. S. M. Elkatlawy, et al., 'Structural properties, linear, and non-linear optical parameters of ternary $\operatorname{Se} 80 \mathrm{Te}(20-\mathrm{x})$ Inxchalcogenide glass systems', Bol. Soc. Esp. Cerám. Vidr. (2020). https://doi.org/10.1016/j.bsecv.2020.09.007 
[31]. S.R. Kodigala, Optical Properties of I-III-VI2 Compounds, 2010, pp. 195-317, http://dx.doi.org/10.1016/B978-0-12-373697-0.00005-5.

[32]. A. S. Hassanien and I. Sharma, J. of Optik, Optical properties of a-Ge 15-x $\mathrm{Sb}_{\mathrm{x}} \mathrm{Te}_{35}$ thyermally evaporated thin films:refractive index dispersion and single oscillator parameters, 200(2020) 163415. https://doi.org/10.1016/j.ijleo.2019.163415

[33]. A. S. Hassanien, I. Sharma Band-gap engineering, conduction and valence band positions of thermally evaporated amorphous Ge15-x Sbx Se50 Te35 thin films: Influences of Sb upon some optical characterizations and physical parameters' J. of Alloys and Compounds (2019)750-763. https://doi.org/10.1016/j.jallcom.2019.05.252.

[34]. N. F. Mott and E. A. Davis, 'Electronic Process in Non- Crystalline Materials,' ClaRendon Press, Oxford, (1979).

[35]. Y. B. Saddeek, K. Aly, G. Abbady, N. Afify, K. S. Shaaban, and A. Dahshan,'Optical and structural evaluation of bismuth alumina-borate glasses doped with different amounts of $\left(\mathrm{Y}_{2} \mathrm{O}_{3}\right)^{\prime}$ J. Non. Cryst. Solids 454 (2016) 13-18. https://doi.org/10.1016/j.jnoncrysol.2016.10.023

[36]. A. M. El Nahrawy, A. A. Moez, et al.,' Sol-Gel Preparation and Spectroscopic Properties of Modified Sodium Silicate /Tartrazine Dye Nanocomposite' Silicon 10, 2117 (2018) 2117-2122.

[37]. P. Sharma and S. C. Katyal, ' Determination of optical parameters of $a$ $\left(\mathrm{As}_{2} \mathrm{Se}_{3}\right)_{90} \mathrm{Ge}_{10}$ thin film' J. Phys. D. Appl. Phys. 40, 2115 (2007).

[38]. M. Khashan and A. El-Naggar,' A new method of finding the optical constants of a solid from the reflectance and transmittance spectrograms of its slab

' Opt. Commun. 174 (2000) 445-453.https://doi.org/10.1016/S0030-4018(99)00721-X

[39]. H. M. Gomaa, ' Influence of $\mathrm{Bi}_{2} \mathrm{O}_{3}$ on the physical and electrical properties of some BoroIron glasses 'J. Non. Cryst. Solids 481, $51 \quad$ (2018). https://doi.org/10.1016/j.jnoncrysol.2017.10.012

[40]. A. S. Hassanien,'Studies on dielectric properties, opto-electrical parameters and electronic polarizability of thermally evaporated amorphous $\mathrm{Cd}_{50} \mathrm{~S}_{50-\mathrm{x}} \mathrm{Se}_{\mathrm{x}}$ thin films' J. Alloys Compd. 671, 566 (2016). https://doi.org/10.1016/j.jallcom.2016.02.126 